\title{
Assessment of time of sexual initiation and its associated factors among students in Northwest Ethiopia
}

\author{
Habtamu Mellie Bizuayehu', Direslgne Misker $\mathrm{Abyu}^{2}$, Hailu Fekadu Demessie ${ }^{3}$ \\ ${ }^{1}$ Debre Markos University, College of medicine and health science, public health department, Debre Markos, Ethiopia \\ ${ }^{2}$ Arba Minch University, Department of Public Health, Arba Minch, Ethiopia \\ ${ }^{3}$ Adama University, Department of Public Health, Asela, Ethiopia
}

Email address:

habtamumellie@yahoo.com (H. M. Bizuayehu), diresmisker@gmail.com (D. M. Abyu), hailufekadu18@yahoo .com (H. F. Demessie)

\section{To cite this article:}

Habtamu Mellie Bizuayehu, Direslgne Misker Abyu, Hailu Fekadu Demessie. Assessment of Time of Sexual Initiation and Its Associated Factors among Students in Northwest Ethiopia. Science Journal of Public Health. Vol. 3, No. 1, 2015, pp. 10-18.

doi: $10.11648 /$ j.sjph.20150301.13

\begin{abstract}
Introduction: As many evidences showed, commencing sex at younger age was risk for acquiring HIV (Human Immunodeficiency Virus) and other sexually transmitted infections (STIs) and of experiencing unplanned Pregnancy due to practicing of it without plan/ not using protective materials. In North East Ethiopia, of half (51.3\%) of youths initiated sex at median age of 17 years, $39.1 \%$ of them were practicing without plan, three quarter $(73.1 \%)$ were not discussing about contraception and half of them were having more than one sexual partner. In northwest Ethiopian students, the prevalence of HIV infection, and other STIs was $1.1 \%$, and $10.7 \%$ respectively and a quarter $(24.3 \%)$ of students was experiencing pregnancy that was ended with abortion (89\%). In parallel, about half of students in similar area was commencing sex at mean age of about 17 years and about half (47.2\%) students were having more than one sexual partner though less than half (45.2\%) of them were using condom during sexual practice. In the presence of earlier sexual onset and its consequences, there is no prior local evidence. Therefore the current study is aimed to calculate time of sexual debut and to determine its associated factors. Methodology: The study was conducted among 326 systematically selected day time regular Debre Markos preparatory (grade 11-12 $2^{\text {th }}$ ) students. Data was collected by pretested Amharic (local language) version self-administered questionnaire. A coded questionnaire was entered by EpiData version 3.1 and analyzed by SPSS version 20. Time of sexual onset was estimated using the actuarial life table and Kaplan Meier survival. Log rank test was used to compare age of sexual debut across categories of categorical variable. Cox proportional-hazard model was used to calculate hazard rate and to determine independent predictors of outcome. Result: Above one third (37.7\%) participants were commencing sex. The median time of sexual initiation was 16 years. Of those beginning sex, about $40.7 \%$ were not using condom during sex. In multivariate Cox proportional hazard model, predictors that are risk for younger age sexual onset were being female, rural resident, smoker, alcohol drinker, and watching pornography movies. Thus organizations working on school youths should further work to enhance age of sexual onset by giving especial attention for risk groups.
\end{abstract}

Keywords: Age of Sexual Initiation, Sexual Practice, HIV, STI, youth, Student, Ethiopia

\section{Introduction}

The sexual experimentations that take place during adolescence can contribute to an increased risk of contracting HIV and other sexually transmitted infections (STIs) and of experiencing unplanned Pregnancy [1-2]. Early debut of sexual intercourse has been shown to be a risk factor for teenage pregnancy [3-6] and sexually transmitted diseases [3, 7-15] and it is associated with greater risk of HIV infection [16-18]. And HIV/AIDS is the current issue, in which about
35.3 million People which includes 2.1 million adolescents, worldwide are currently living with HIV/AIDS. Among 2.3 million new HIV infections occurred globally, more than half of it was occur on youths (15-24years) [19].

In Rural Eastern Cape Province, South Africa about 2\% and $12.4 \%$ of the men and women respectively $15-26$ years aged were HIV positive [20, 21].

In 2010, it is estimated that 1.5 million Ethiopians are living with HIV/AIDS [22] and young people (15-24years) accounted for $42 \%$ of new HIV infection [23]. According to the 2011 Ethiopian Demographic health survey around 1 
percent youth age 15-24 were positive for HIV. One percent of women and men reported having had STI in the past 12 months in the survey [24]. The sero-prevalence of HIV infection and the reported history of sexually transmitted diseases in North West Ethiopia among Gondar high school students was $1.1 \%$ and $10.7 \%$ respectively [25].

In the presence of the risk for acquiring HIV infection, sexually transmitted diseases and unplanned pregnancy, Adolescents who are younger at first sexual intercourse are less likely to use contraceptive and other protective methods [26-28].

A combined demographic health survey data, DHS/AIS data (2000-2010), in sub-Saharan Africa showed Up to $25 \%$ of 15- to 19-year-old adolescents reported sex before age 15 . The finding showed as many 15- to 19-year-olds are at risk of HIV / STIs and unplanned pregnancies because of multiple partnerships and insufficient condom and other contraceptive use [29].

In United States from 2006-2010 data, about $43 \%$ of female teenagers and about $42 \%$ of male teenagers had had sexual intercourse at least once though only $78 \%$ of females and $85 \%$ of males used a method of contraception [30]. In same country men with sexual debut at less than age 15 were more likely to report risk behaviors at first sexual experience: no condom use (19\%), a casual partner $(26.8 \%)$, and not feeling they had been "ready and wanted to have sex" (19.5\%) [31]. Other study in similar country also showed about $12.9 \%$ sexually active students did not use any contraceptive method and $22.1 \%$ of them drank alcohol and using drugs before sex [32].

In northwest Ethiopia about $45 \%$ out-of-school adolescents' age 10-19 years were reported sexual commencement. Their mean age at first sexual onset was 13.6 years though about $21 \%$ adolescents' use modern contraceptive [33].

In Harar, Eastern Ethiopia, nearly half of male and onefifth of female youth's age 14-29 years old reported as initiated sex at the mean age of 16.9 years. Among $69.3 \%$ of males and $63.9 \%$ of females having favorable knowledge about family planning only about one-fourth reported ever having used a method. About $15 \%$ of females had experienced unwanted pregnancies and youths knew the time of ovulation and when pregnancy would occur were only a little over half [34].

In Northwest Ethiopia, about one third (30.8\%) unmarried female students in Bahir dar town high schools were commencing sex at mean age of 16.46 years. About half (47.2) students were having two or more sexual partner though only $32.9 \%$ of them use condom always. A quarter $(24.3 \%)$ of students was having history of pregnancy although majority (89\%) of it ended with abortion [35]. In North East Ethiopia, a half (51.3) of youths, age 15-24 years was initiated sex at median age of 17 years. However, $39.1 \%$ sexual initiations were unplanned and before sex, about three quarter (73.1) of youths were not discussing about contraception. Half of them were having more than one sexual partner in their life time. Of those committing sex with a non-regular (causal) sexual partner (14.2\%) only $36 \%$ of them used condom regularly [36].

A study in Gondar, Northwest Ethiopia preparatory level students showed as $65 \%$ of male and $35 \%$ of female students already initiated sexual intercourse at mean age of 17.3 and 17.1 years respectively [37]. In similar area, high school level students mean age of sexual commencement was 16.9 years and about half $(54.8 \%)$ of them did not use condoms [25].

A quarter $(26.3 \%)$ of Northern Ethiopia high school students were started sexual intercourse and about $35 \%$ of them have casual friends [38]. Similarly a quarter $(24.8 \%)$ of in-school adolescents in Eastern Ethiopia was commencing $\operatorname{sex}[39]$.

As different evidences showed early sexual initiation were risk for acquiring HIV/AIDS and STDS and unwanted pregnancy $[1-16,18,21,26-27,40]$ thus the current study is aimed to calculate time of sexual debut and to determine its associated factors since there is no prior local evidence up to our effort. The evidence is expected to merit to plan reproductive health commodities and for formulation of policy issues at school.

\section{Methods and Materials}

\subsection{Study Design and Setting}

A cross sectional study among preparatory (grade 11-12 $2^{\text {th }}$ ) school students in Debre Markos town was conducted using quantitative research method. Debre Markos town is found in eastern direction of Amhara region about 256 Kilometer from Bihar Dar [capita town of Amhara region] and 299 kilometer from Addis Ababa [capital town of Ethiopia]. The study was conducted in March, 2014. All day time regular students in age range of 15-24 who were attending Debre Markos preparatory (grade $11-12^{\text {th }}$ ) school at time of data collection were the study populations.

\subsection{Sample Size Determination and Sampling Procedure}

The sample size was calculated based on the assumption of 95\% confidence interval, 5\% margin of error and the proportion of sexual initiation $(72 \%)$ from previous study [41]. The required sample size calculated using OpenEpi Version 2.3, May 2009 was 310. After adding 7\% nonresponse rate the final sample size was 332 .

The list of students were available in the school registrar thus the sampling frame were prepared by excluding students who were not attending school due to drop out and other reasons. Then selection of participants was made by applying simple random sampling procedure using random number table.

\subsection{Data Collection Procedure}

Data collection questionnaire was developed by reviewing different literatures. It was translated in to local language [Amharic] and back translated in to English to maintain consistency. Ten percent of the questionnaires were pretested in Amber preparatory school and errors identified during pre-test were corrected accordingly. Data was 
collected by self-administered questionnaire and responses were collected in secret ballot. Thus the role of data collectors was clarifying the question if respondents ask during filling/responding of the questionnaire.

Data collectors and supervisors were trained by principal investigators about the objective of the study, confidentiality of information and the contents of the questionnaire in detail.

\subsection{Operational Definition}

Sexual initiation: all sex acts that are penetrative penile to vaginal [18].

Having Comprehensive knowledge on HIV/AIDS: if identify the two important prevention ways (being faithful and condom use), being aware that a healthy-looking person can have HIV and reject the two locally common misconceptions about HIV transmission (mosquito bite and sharing food) [24].

Alcohol use: if study participant responds yes to the question 'Have you ever drunk alcohol in your life?' [24].

Khat use: if study participant responds yes to the question 'Have you ever chewed khat in your life?'[24].

Smoker: if study participant responds yes to the question 'Have you ever smoking cigarettes in your life? [24].

\subsection{Data Processing and Analysis}

Each questionnaire were given a code and entered in to EpiData version 3.1 statistical package and exported to SPSS version 20 statistical package for analysis. Before analysis, data cleaning using frequency, listing and sorting was done to identify any outliers and missed values and then corrections were made by revising the original questionnaire. The actuarial life table and Kaplan Meier survival was used to estimate time of sexual initiation. Log rank test was used for categorical variables to compare age of sexual debut curves across each stratum. Before running the Cox regression model, assumption of proportional-hazard and multicolinearity was checked. Assumption of proportional-hazard was checked by Schoenfeld residual with pvalue $\geq 0.1(\alpha=10 \%)$ and the assumption was not violated. Multi-colinearity was checked using tolerance/variance inflation factor and we are not found multi-colilearity. Cox proportional-hazard model was used to calculate the univariate and multivariate crude and adjusted hazard rates respectively and to determine independent predictors of outcome. In multi-variate cox proportional hazard model, only those variables which were associated with outcome with $\mathrm{p}$-value $\leq 0.1$ in uni-variate analysis and not collinear were entered to the final model. The cut off point for significant association was $\mathrm{P}$-value $<0.005$.

\subsection{Data Quality Management}

To maintain data quality training was given for data collectors and for supervisors. Properly designed data collection material was developed by reviewing different literatures. Supervision was carried out on daily base to check completeness and consistency of the questionnaire response both by the supervisors and the principal investigators. The data was double entered by trained data clerk to heck correct data entry. In addition, at the end of data entry data cleaning was done using frequencies, cross tabulations, sorting and listing to check missed values and outliers.

\subsection{Ethical Consideration}

The ethical clearance was given by Debre Markos university ethical committee. In addition permission to conduct the study was obtained from the concerned bodies of Debre Markos town and the school. To protect confidentiality no personal identifier was recorded in the questionnaire. Written informed consent was obtained from study participants.

\section{Result}

A total of 326 students were participated in the study, making a response rate of $98.2 \%$. The mean (SD) age of participants was $18.56(0.95)$ and majority $(86.2 \%)$ of them were below age of 19 years. Above half of them were males (53.7\%), living in urban (56.4\%), grade 12 students $(52.5 \%)$ and living with their family at time of data collection $(56.7 \%)$. All most all $(95.4 \%)$ of them were following Orthodox religion. About one third (34\%) participants were having comprehensive HIV/AIDS knowledge. Above one out of hundred participants were drinking alcohol (13.2\%), chewing chat (14.7\%), and smoking cigarrete (10.7\%). A quarter (26.4\%) of participants was having a habit of watching pornography videos (Table 1).

\subsection{Sexual Initiation Time and Associated Factors}

Above one third $(37.7 \%)$ participants were commencing sex and majorities $(66.9 \%)$ of them start at 17 years old or younger. According to Kaplan-Meier survival estimation, the median time of sexual initiation was 16 years $(95 \%$ CI, 15.516.5) and as estimation of Actuarial life table showed, the probability of not initiating sex up to age of 18 years for males and females was $7 \%$ and $2 \%$ respectively while in age of 20 it is $<0.001 \%$ in both sexes (Table 2, figure 1). Among those beginning sex, about $40.7 \%$ were not using condom during sex.

In log rank test using Kaplan-Meier survival, variables having significant difference $(\mathrm{p}<0.05)$ in strata were age group $(p=0.023)$, sex $(p=0.015)$, residence $(p<0.0001)$, alcohol drinking status $(\mathrm{p}<0.0001)$, watching pornographic videos status $(\mathrm{p}<0.0001)$ and cigarette smoking status $(\mathrm{p}=0.009)$ (Table 1). 
Table 1. socio-demographic and other characteristics of the students in Debre Markos town in 2014.

\begin{tabular}{|c|c|c|c|c|}
\hline \multirow{2}{*}{ Variables } & \multicolumn{2}{|l|}{ Begin sex } & \multirow{2}{*}{ Total (\%) } & \multirow{2}{*}{$\begin{array}{l}\text { Log rank test } \\
\text { p-value }\end{array}$} \\
\hline & Yes $(\%)$ & No $(\%)$ & & \\
\hline \multicolumn{5}{|l|}{ Age group } \\
\hline$<19$ & $90(32)$ & 191(68) & $281(86.2)$ & 0.023 \\
\hline$>=19$ & $33(73.3)$ & $12(26.7)$ & $45(13.8)$ & \\
\hline \multicolumn{5}{|l|}{ Religion } \\
\hline Orthodox & $117(37.6)$ & $194(62.4)$ & $311(95.4)$ & 0.061 \\
\hline other & $6(40)$ & $9(60)$ & $15(4.6)$ & \\
\hline \multicolumn{5}{|l|}{ Grade } \\
\hline 11 & $41(26.5)$ & $114(73.5)$ & $155(47.5)$ & 0.433 \\
\hline 12 & $82(48)$ & $89(52)$ & $171(52.5)$ & \\
\hline \multicolumn{5}{|l|}{ Sex } \\
\hline Male & $64(36.6)$ & $111(63.4)$ & $175(53.7)$ & 0.015 \\
\hline Female & $59(39.6)$ & $92(60.9)$ & $151(46.3)$ & \\
\hline \multicolumn{5}{|l|}{ Residence } \\
\hline Urban & $53(35.8)$ & $95(64.2)$ & $148(56.4)$ & $<0.0001$ \\
\hline \multicolumn{5}{|c|}{ Currently living with } \\
\hline Family & $68(36.8)$ & $117(63.2)$ & $185(56.7)$ & \\
\hline Relative & $10(41.7)$ & $14(58.3)$ & $24(7.4)$ & 0.066 \\
\hline Friend & $18(39.1)$ & $28(60.9)$ & $46(14.1)$ & \\
\hline Alone & $27(38)$ & $44(62)$ & $71(21.8)$ & \\
\hline \multicolumn{5}{|c|}{ Family monthly income } \\
\hline$<100$ dollar & $61(40.4)$ & $90(59.6)$ & $151(46.3)$ & 0.377 \\
\hline$>=100$ dollar & $62(35.4)$ & $113(64.6)$ & $175(53.7)$ & \\
\hline \multicolumn{5}{|c|}{ Parental occupation } \\
\hline Unemployed & $89(35.6)$ & $161(64.4)$ & $250(76.7)$ & 0.88 \\
\hline Employed & $34(44.7)$ & $42(55.3)$ & $76(23.3)$ & \\
\hline \multicolumn{5}{|c|}{ Comprehensive HIV/AIDS knowledge } \\
\hline Good & $39(35.1)$ & $72(64.9)$ & 111(34) & 0.076 \\
\hline Poor & $84(39.1)$ & $131(60.9)$ & $215(66)$ & \\
\hline \multicolumn{5}{|c|}{ Drinking alcohol } \\
\hline Yes & $30(69.8)$ & $13(30.2)$ & 43(13.2) & $<0.0001$ \\
\hline Yes & $36(75)$ & $12(25)$ & $48(14.7)$ & 0.132 \\
\hline No & $87(31.3)$ & $191(68.7)$ & $278(85.3)$ & \\
\hline \multicolumn{5}{|c|}{ Smoking cigarettes } \\
\hline Yes & $24(68.6)$ & $11(31.4)$ & $35(10.7)$ & 0.009 \\
\hline No & $99(34)$ & 192(66) & 291(89.3) & \\
\hline \multicolumn{5}{|c|}{ Watching pornographic movies } \\
\hline Yes & $54(62.8)$ & $32(37.2)$ & $86(26.4)$ & $<0.0001$ \\
\hline No & $69(28.8)$ & $171(71.2)$ & 24.(73.6) & \\
\hline
\end{tabular}

Table 2. Actuarial life table estimation of age at sexual initiation of students in Debre Markos town in 2014.

\begin{tabular}{|c|c|c|c|c|c|c|}
\hline $\begin{array}{l}\text { First-order } \\
\text { Controls } \\
\end{array}$ & $\begin{array}{l}\text { Interval Start } \\
\text { Time }\end{array}$ & $\begin{array}{l}\text { Proportion } \\
\text { Terminating } \\
\end{array}$ & $\begin{array}{l}\text { Proportion } \\
\text { Surviving } \\
\end{array}$ & $\begin{array}{l}\text { Cumulative Proportion } \\
\text { Surviving at End of Interval }\end{array}$ & $\begin{array}{l}\text { Probability } \\
\text { Density }\end{array}$ & $\begin{array}{l}\text { Hazard } \\
\text { Rate }\end{array}$ \\
\hline \multirow{17}{*}{ female } & 0 & .00 & 1.00 & 1.00 & .000 & .00 \\
\hline & 2 & .00 & 1.00 & 1.00 & .000 & .00 \\
\hline & 4 & .00 & 1.00 & 1.00 & .000 & .00 \\
\hline & 6 & .00 & 1.00 & 1.00 & .000 & .00 \\
\hline & 8 & .00 & 1.00 & 1.00 & .000 & .00 \\
\hline & 10 & .11 & .89 & .89 & .056 & .06 \\
\hline & 14 & .19 & .81 & .69 & .083 & .11 \\
\hline & 16 & .48 & .52 & .36 & .167 & .32 \\
\hline & 18 & .81 & .19 & .07 & .146 & .68 \\
\hline & 20 & 1.00 & .00 & .00 & .035 & 1.00 \\
\hline & 0 & .00 & 1.00 & 1.00 & .000 & .00 \\
\hline & 2 & .00 & 1.00 & 1.00 & .000 & .00 \\
\hline & 4 & .00 & 1.00 & 1.00 & .000 & .00 \\
\hline & 8 & .00 & 1.00 & 1.00 & .000 & .00 \\
\hline & 10 & .16 & .84 & .84 & .078 & .09 \\
\hline & 12 & .16 & .84 & .71 & .069 & .09 \\
\hline & 14 & .19 & .81 & .57 & .069 & .11 \\
\hline
\end{tabular}




\begin{tabular}{|c|c|c|c|c|c|c|}
\hline $\begin{array}{l}\text { First-order } \\
\text { Controls } \\
\end{array}$ & $\begin{array}{l}\text { Interval Start } \\
\text { Time }\end{array}$ & $\begin{array}{l}\text { Proportion } \\
\text { Terminating }\end{array}$ & $\begin{array}{l}\text { Proportion } \\
\text { Surviving } \\
\end{array}$ & $\begin{array}{l}\text { Cumulative Proportion } \\
\text { Surviving at End of Interval }\end{array}$ & $\begin{array}{l}\text { Probability } \\
\text { Density }\end{array}$ & $\begin{array}{l}\text { Hazard } \\
\text { Rate }\end{array}$ \\
\hline & 16 & .66 & .34 & .20 & .186 & .49 \\
\hline & 18 & .90 & .10 & .02 & .088 & .82 \\
\hline & 20 & 1.00 & .00 & .00 & .010 & 1.00 \\
\hline
\end{tabular}

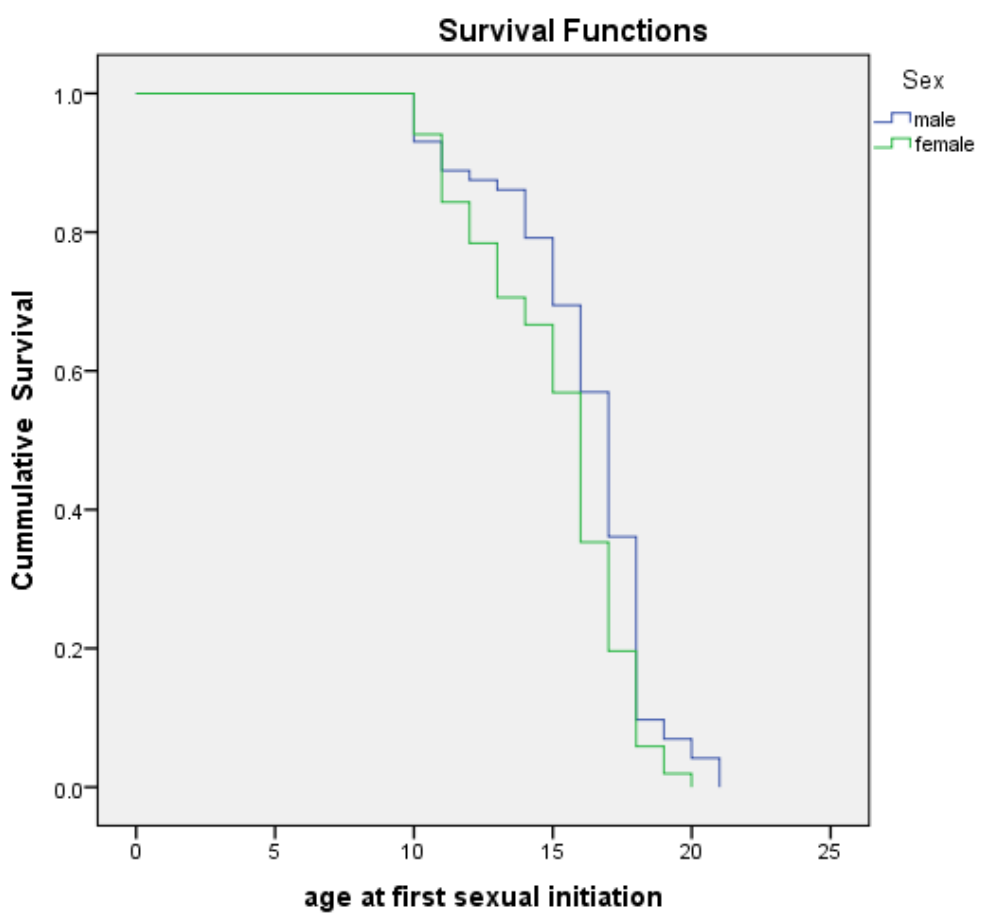

Fig. 1. Kaplan-Meier survival estimation of trough time progression to initiate sex among students in Debre Markos town in 2014.

As Cox proportional hazard model after adjustment for potential confounders showed, females were 1.9 times more likely to initiate sex at younger age than males. Rural side students were 1.7 times commencing sex earlier than urban ones. In the same manner, those students who were smokers, drinking alcohol, and watching pornography movies were 2.5 , 1.9 , and 1.6 times respectively more likely beginning sex at early age compared to their counter parts (Table 3 ).

Table 3. predictors of time for sexual commencement in Cox proportional hazard model among students in Debre Markos town in 2014.

\begin{tabular}{|c|c|c|c|}
\hline \multirow{2}{*}{ Variables } & \multirow[t]{2}{*}{ KMMS(95\% CI) } & \multicolumn{2}{|l|}{ Hazard rate $(95 \% \mathrm{CI})$} \\
\hline & & Crude & Adjusted \\
\hline \multicolumn{4}{|l|}{ Sex } \\
\hline female & $17(15.39-16.61)$ & $1.457(1.012-2.098)$ & $1.927(1.261-2.944)$ \\
\hline Male & $16(16.47-17.53)$ & 1 & 1 \\
\hline \multicolumn{4}{|l|}{ Residence } \\
\hline Rural & $15(13.97-16.03)$ & $1.928(1.322-2.811)$ & $1.672(1.086-2.573)$ \\
\hline Urban & $17(16.54-17.46)$ & 1 & 1 \\
\hline others & $15(12.74-17.26)$ & $484(0.21-1.116)$ & $1.349(0.535-3.399)$ \\
\hline Orthodox & $16(15.48-16.52)$ & 1 & 1 \\
\hline \multicolumn{4}{|l|}{ watch pornographic movies } \\
\hline yes & $15(13.89-16.11)$ & $1.863(1.286-2.697)$ & $1.589(1.003-2.517)$ \\
\hline no & $17(16.33-17.67)$ & 1 & 1 \\
\hline \multicolumn{4}{|l|}{ Drinking alcohol } \\
\hline yes & $14(12.39-15.61)$ & $2.786(1.798-4.315)$ & $1.826(1.047-3.183)$ \\
\hline yes & $15(14.04-15.96)$ & $1.715(1.080-2.725)$ & $2.473(1.152-5.305)$ \\
\hline no & $16(15.50-16.61)$ & 1 & 1 \\
\hline \multicolumn{4}{|l|}{ Chewing khat } \\
\hline yes & $16(15.22-16.78)$ & $1.289(0 . .869-1.910)$ & $0.658(0.361-1.201)$ \\
\hline no & $16(15.35-16.65)$ & 1 & 1 \\
\hline
\end{tabular}

Key,

KMMS-Kaplan-Meier median survival

CI-confidence interval 


\section{Discussion}

The current finding of sexual debut $(37.7 \%)$ is nearly in agreement with sexual onset of Flemish secondary school students' (35\%) [42] and Busan, Korea college students' $(41.4 \%)$ [43]. And the finding was higher than combined demographic health survey data between 2000-2010 in subSaharan Africa (25\%) [29], in-school adolescents in Eastern Ethiopia (24.8\%) [39], high school students in Northern Ethiopia (26.3\%) [38] and it was lower when compared with a study in Brazilian adolescents $(61.6 \%)$ [44], teenagers in United States (about $43 \%$ of females and $42 \%$ males had beginning sex) [30], youths in North East Ethiopia (51.3\%) [36], out-of-school adolescents in Northwest Ethiopia (45\%) [33] and Gondar high school students in North West Ethiopia $(50 \%)$ [25].The possible discrepancy would be differences in age of study participants included in different studies (example 10-19 [33], 15-19 [29], 16-19 [44], 15-24 [36], 1736 [43]), time gap between the studies, differences in age of marriage in different areas or inclusion/exclusion of married participants which is the main reason for sexual initiation [24, $33,45]$, variations in mass advertisement on sexual abstinence to prevent HIV/AIDS, technological advancements for viewing pornography videos which was risk for early sexual onset [35, 36, 43, 46, 47].

The estimated median time of sexual initiation (16 years old) in this study was nearly in line with studies done in Debre-berhan Town, Ethiopia (16.4 years) [48], Gondar town, North West Ethiopia (16.9 years) [25], Dessie, north east Ethiopia (16.8 years) [45], Eastern Ethiopia (15.6 years) [39], Harar, Eastern Ethiopia (16.9 years) [34], Butajira, southern Ethiopia (16 years) [33], Spain (16.3 years) [49] and in Italy (16 years) [49]. However, it was slightly higher than studies conducted in Kolladiba, North West Ethiopia (15 years) [36], Gojjam, North West Ethiopia (13.5 years) [50], East Gojjam zone, northwest Ethiopia (13.6 years) [33], Central Scotland (14 years) [51], Brazil (14.9 years) [44], and Peru (14.3 years) [49], and the finding was Lower than a studies in North East Ethiopia (17 years) [36], Butagira, Ethiopia (17years) [45], Gamo Gofa, South West Ethiopia (17.07 years) [41], rural Zimbabwe (18.5 years) [16], and Busan, Korea (21 years for males) [43]. Reasons for differences of figures in prior studies among each other and with current study might be variations in using numerical summary measures i.e. reporting of mean vs median, time elapsed between studies, age differences of study population, socio-cultural and behavioral variations of study participants.

The current finding of median sexual debut in urban and rural students at age 15 and 17 years respectively was comparable with a study in North East Ethiopia among youths of age 15-24 [36]. The finding of not using condom during sex $(40.7 \%)$ in this study was in parallel with other studies [20, 25, 35].

In this study females were 1.9 times more likely initiating sex at younger age than males and the finding was in line with studies $[33,36,52]$ and contradicts with studies $[43,53]$.
A study in northwest Ethiopia showed as females begin sex 3.2 times $(\mathrm{AOR}=3.24,95 \% \mathrm{CI}$ : 2.0-5.3) more earlier than males [33] and other study in similar area also showed as females were 1.6 times $(\mathrm{AOR},=1.56,95 \% \mathrm{CI}: 1.11-2.19)$ risk for commencing sex before males [36]. Males tended to have 2.5 times $(\mathrm{AHR}=2.518,95 \% \mathrm{CI}: 1.710-3.707)$ more sexual experience than females in college students in Busan, Korea [43] this disagreement with current study can be attributed by age dissimilarity of study population i.e. 17-36 years [43] vs 15-24 years in current study.

The current finding of rural students commencing sex earlier than urban ones was in agreement with other studies [33, 36, 46, 51]. A study in northwest Ethiopia showed as sexual activity was 3 times $(\mathrm{AOR}=3.0,95 \% \mathrm{CI}$ : 1.93-6.24) more common in rural youths of age 10-19 years [33]. Urban resident students in Northern Ethiopia were $23 \%$ times $(\mathrm{AOR}=0.23,95 \% \mathrm{CI}: 0.070 .75)$ less likely practicing sex at younger age [46].

The current finding revealed as those smokers and alcohol drinkers commence sex at earlier age and the result was similar with other studies [36, 43, 45, 51, 53]. College students in Busan, Korea who were alcohol drinkers and smokers were 1.8 times $(\mathrm{AHR}=1.787,95 \% \mathrm{CI}$ : $1.222-2.615)$ and 1.9 times $(\mathrm{AHR}=1.958,95 \% \quad \mathrm{CI}: 1.535-2.498)$ respectively more likely debut sex at younger age compared their counter parts [43]. Youths drinking alcohol in North East Ethiopia were begin sex about 2.2 times $(\mathrm{AOR}=2.16,95 \%$ CI: 1.12-4.18) than non-drinkers [36].

In this study participants' watching pornography videos were 1.6 times more early starting sex than their counter parts and the result was supported by other studies $[35,36$, 43, 46, 47]. College students in Busan, Korea who had experienced pornography had 1.8 times more sex at younger age than those not experienced pornography $(\mathrm{p}=.005)$ [43]. In Bahir Dar town northwest Ethiopia female youths' watching of pornographic video were 10.2 times $(\mathrm{AOR}=10.15,95 \%$ CI: 6.63-15.53) at risk for beginning sex at younger age before marriage [35].

In current study, using probability selection of participants and self-administered questionnaire would be used for representativeness of the result and to decrease social desirability bias respectively considered as strong side of the paper. On the other hand, the paper would have recall bias for questions asking prior memory like age of sexual initiation and social desirability bias would also happen due to having sensitive questions like substance use, sexual debut though efforts made to reduce it by using self-administered questionnaire and collection of response in secret ballot.

\section{Conclusion and Recommendation}

Above one third participants was commencing sex at median age of 16 years though only slightly above two third of them were using condom during sexual practice. Students who were female, smoker, alcohol drinker, watching pornography videos and living rural area were initiating sex 
at younger age than their counter parts. Thus the school administrator, youth clubs, and other interested organizations working on school youths should further work to enhance age of sexual onset by giving especial care for female, rural, smoker, alcohol drinker and pornography movie observer students.

\section{Acknowledgment}

We want to thank Debre Markos town administration and the responsible school managers for their permission to conduct this study. In addition we would thank our study participants for their willingness to take part in the study.

\section{References}

[1] Lloyd CB Growing Up Global: The Changing Transitions to Adulthood in Developing Countries: Executive Summary:In (eds Countries., P. O. T. T. A. I. D., Committee on Population and Board on Children, Y., and Families \&Education.,D. O. B. A. S. S. A.) The National Academies Press, Washington DC, 2005: $1-14$

[2] Dixon-Mueller R. Starting young: sexual initiation and HIV prevention in early adolescence. AIDS and Behavior 2009; 13:100-109.

[3] Edgardh K. Sexual behaviour and early coitarche in a national sample of 17 year old Swedish girls. Sex Transm Infect 2000; 76:98-102. [PubMed: 10858710]

[4] Humblet O, Paul C, Dickson N. Core group evolution over time: high-risk sexual behavior in a birth cohort between sexual debut and age 26. Sex Transm Dis 2003; 30:818-24. [PubMed: 14603088]

[5] Buston K, Williamson L, Hart G. Young women under 16 years with experience of sexual intercourse: who becomes pregnant? J Epidemiol Community Health 2007; 61:221-5. [PubMed:17325399]

[6] Division of STD Prevention. Sexually Transmitted Disease Surveillance. Atlanta: Centers for Disease Control and Prevention. 2000

[7] Niccolai LM, Ethier KA, Kershaw TS, Lewis JB, Meade CS, Ickovics JR. New sex partner acquisition and sexually transmitted disease risk among adolescent females. J Adolesc Health2004; 34:216-23. [PubMed: 14967345]

[8] Finer LB, Darroch JE, Singh S. Sexual partnership patterns as a behavioral risk factor for sexually transmitted diseases. FamPlannPerspect 1999; 31:228-36. [PubMed: 10723647]

[9] Kahn JA, Rosenthal SL, Succop PA, Ho GY, Burk RD. Mediators of the association between age of first sexual intercourse and subsequent human papillomavirus infection. Pediatrics 2002; 109:E5. [PubMed: 11773573]

[10] Abma J.C. and F.L. Sorenstein. Sexual Activity and Contraceptive Practices among Teenagers in the United States. 1988 and 1995 Series 23: Data from the National Survey of Family Growth No. 21. U.S. Department of Health and Human Services. 2002.
[11] Burk, R.D., G.Y. Ho, L. Beardsley, M. Lempa, M. Peters, and R. Bierman. Sexual Behavior and Partner Characteristics are the Predominant Risk Factors for Genital Human Papilloma Virus Infection in Young Women. Journal of Infectious Diseases 1996; 174:679-89.

[12] Burkett B.J, C.M. Peterson, L.M. Birch, C. Brennan, M.L. Nuchols, and B.E. Ward. The Relationship Between Contraceptives, Sexual Practices, and Cervical Human Papilloma Virus Infection Among a College Population. The Journal of Clinical Epidemiology 1992; 45: 1295-302.

[13] Kahn J.A., S.L. Rosenthal, P.A. Succop G.Y.F. Ho, and R.D. Burk. The Interval Between Menarche and Age of First Sexual Intercourse as a Risk Factor for Subsequent HPV Infection in Adolescent and Young Adult Women. Journal of Pediatrics 2002; 141:718-23.

[14] Latka M., J. Ahern, R.S. Garfein, L.Ouellet, P. Kerndt, P. Morse,et al. Prevalence, Incidence, and Correlates of Chlamydia and Gonorrhea Among Young Adult Injection Drug Users.Journal of Substance Abuse 2001;13:73-88.

[15] L.C. H. Bauer, A. Reingold, M.H. Schiffman, J.C. Chambers, C.J. Tashiro, and M.M. Manos. Determinants of Genital Human Papilloma Virus Infection in Young Women.Journal of the National Cancer Institute 1991; 83:997-1003.

[16] Simon G., Constance A. N., Geoffrey P G, Peter R.M., Tom Z., Michel C., et al. Sexual mixing patterns and sex-differentials in teenage exposure to HIV infection in rural Zimbabwe. Lancet 2002; 359: 1896-903

[17] Audrey P., KatieO.B.,CatherineM.P.,William C.M. and Helen R. Early Coital Debut and associated HIV Risk Factors among Young Women and Men in South Africa.International Perspectives on Sexual and Reproductive Health 2009;35(2):74-82.

[18] T B.H., S.Gregson, J.J.C. Lewis, B.A.Lopman, G. P. Garnett. Behavior change in generalized HIV epidemics: impact of reducing cross-generational sex and delaying age at sexual debut. Sex Transm Infect 2007; 83: i50-i54

[19] World Health Organization (WHO) Report on the Global AIDS epidemic. Switzerland, Geneva. 2012.

[20] R.Jewkes, K.Dunkle, M.Nduna, J. Levin, N.Jama, N.Khuzwayo, et al. Factors associated with HIV seropositivity in young, rural South African men. International Journal of Epidemiology 2006;35:1455-1460

[21] R.Jewkes, K.Dunkle, M. Nduna, J. Levin, N.Jama, N.Khuzwayo, et al. Factors associated with HIV sero-status in young rural South African women: connections between intimate partner violence and HIV. International Journal of Epidemiology 2006;35:1461-1468

[22] Federal Democratic Republic of Ethiopia (FDRE), Country progress report on HIV/AIDS response. Addis Ababa, Ethiopia. 2012.

[23] Federal Democratic Republic of Ethiopia, ministry of health/national HIV/AIDS prevention and control office, AIDS in Ethiopia six report. Addis Ababa, Ethiopia. 2010.

[24] Central Statistical Agency (CSA) (2011) Ethiopia Demographic and Health Survey; final draft report. ICF International Calverton, Maryland, USA. 
[25] Gashaw A., Afework K., Feleke M., Yigzaw K., Molla G.et al.Low prevalence of HIV infection and knowledge, attitude and practice on HIV/AIDS among high school students in Gondar, Northwest Ethiopia. Ethiop.J.HealthDev2007; 21(2):179-182.

[26] Abma, J., A. Chandra, W. Mosher, L. Peterson, and L. Piccinino. Fertility, Family Planning, and Women's Health: New Data From the 1995 National Survey of Family Growth.Vital Health Statistics, Series 23, No. 19. Hyattsville, MD: National Center for Health Statistics. 1997.

[27] Mosher W.D. and J.W. McNally.Contraceptive Use at First Premarital Intercourse: United States, 1965-1988.Family Planning Perspectives 1991; 23(3):108-16.

[28] Sonenstein F.L., J.H. Pleck, and L.C. Ku.Sexual Activity, Condom Use, and AIDS Awareness Among Adolescent Males. Family Planning Perspectives 1989; 21(4):152-58.

[29] A.M. Doyle1, Sue Napierala M., M.L. Plummer and D.A. Ross. The sexual behavior of adolescents in sub-Saharan Africa: patterns and trends from national surveys Tropical Medicine and International Health July 2012 ; 17: 796-807

[30] Martinez G., Copen C.E., Abma J.C. Teenagers in the United States: Sexual activity, contraceptive use, and childbearing, 2006-2010 National Survey of Family Growth. National Center for Health Statistics. Vital Health Stat 2011; 23(31).

[31] A Harrison, J Cleland, E Gouws, J Frohlich. Early sexual debut among young men in rural South Africa: heightened vulnerability to sexual risk? Sex Transm Infect 2005; 81:259_ 261.

[32] Trends in the Prevalence of Sexual Behaviors and HIV Testing National Youth Risk Behavior Survey: 1991-2011. Visit www.cdc.gov/yrbss or call 800-CDC-INFO (800-232-4636).

[33] Alemayehu S., Mesganaw F., Alemayehu W. Reproductive health needs of out-of-school adolescents: Across-sectional comparative study of rural and urban areas in northwest Ethiopia. Ethiop J Health Dev 2006; 20(1):10-17.

[34] Antenane K., Mesfin H. Sexual behaviour and level of awareness on reproductive health among youths: Evidence from Harar, EasternEthiopia. Ethiop. J. Health Dev.1999;13(2):107-113

[35] YeshalemMulugeta.andYemane B. Factors associated with pre-marital sexual debut among unmarried high school female students in bahir Dar town, Ethiopia: cross- sectional study. Reproductive Health 2014, 11:40. http://www.reproductivehealth-journal.com/content/11/1/40.

[36] Fekadu M., Alemayehu W. Age at sexual initiation and factors associated with it among youths in North East Ethiopia. Ethiop J Health Dev 2009; 23(2):154-162.

[37] Shiferaw Y., Alemu A., Girma A., Getahun F., Kassa A., Gashaw A. et al. Assessment of knowledge, attitude and risk behaviors towards HIV/AIDS and other sexual transmitted infection among preparatory students of Gondar Northwest Ethiopia. BMC research notes 2011; 4:505.

[38] Abraha T. and Berhanu M. Knowledge, attitude and practice regarding HIV/AIDS among secondary school students in Mekelle City, Ethiopia. Afr. J. AIDS 2013;1(1) :001-007.

[39] Lemessa O., Yemane B. and Alemayehu W. Pre-marital sexual debut and its associated factors among in-school adolescents in eastern Ethiopia. BMC Public Health 2012; 12:375. http://www.biomedcentral.com/1471-2458/12/375

[40] R. j. Diclemente, G.M. Wingood, C.SioneAn, R. Crosby, K. Harrington, S. Davies, et al. Association of Adolescents' History of Sexually Transmitted Disease (STD) and Their Current High-Risk Behavior andSTD Status A Case for Intensifying Clinic-Based Prevention Efforts. Sexually Transmitted Diseases September 2002; 29;9

[41] Marelign T. and Gistane A. Factors associated with age at first sexual initiation among youths in Gamo Gofa, South West Ethiopia:a cross sectional study. BMC Public Health 2013; 13:622. http://www.biomedcentral.com/1471-2458/13/622.

[42] Ronan V. R., Hans B., Charlotte V. T. AIDS knowledge and sexual activity among Flemish secondary school students: a multilevel analysis of the effects of type of education. BMC Public Health 2010, 10:30. http://www.biomedcentral.com/1471-2458/10/30.

[43] Young H. K., Nam C. P., Hyun J. P., Eun Y. Y. Factors Associated with the Timing of First Sexual Intercourse Among College Students in Busan, Korea. Korean J Androl. August 2011; 29 (2). http://dx .d oi.org/10.5534/k ja .2 011.29.2.134

[44] Vera P., Gabriela C., Gustavo V., Rita D., Grupo de E.dP., Sexualidade A. Age and condom use at first sexual intercourse of Brazilian Adolescents. Rev SaúdePública 2008;42(1. 1)

[45] Mitike M., Yemane B., BerntL.Traditional values of virginity and sexual behavior in rural Ethiopian youth: results from a cross-sectional study. BMC Publ Health 2008; 8:9.

[46] Getachew M. K., Emebet B. W.\&Nurilign A. M. Prevalence of Premarital Sexual Practice and Associated Factors among Alamata High School and Preparatory School Adolescents, Northern Ethiopia. Global Journal of Medical research: k Interdisciplinary 2014; 14 (3) : 1

[47] Eric W.O., Richard J.B., Jill C.M., Rory C.R. The impact of internet pornography on adolescents: a review of the research. Sex Addict Compuls J Treat Prev 2012, 19(1-2):99-122.

[48] Solomon S., Woldaregay E., Girmay M. and Desalegn W. Perception of High School Students on risk for acquiring HIV and utilization of Voluntary Counseling and Testing (VCT) service for HIV in Debre-berhan Town, Ethiopia: a quantitative cross-sectional study. BMC Research Notes 2014, 7:518. http://www.biomedcentral.com/1756-0500/7/518

[49] Donatella P., Daniela A., Cecilia T., Francesca C., Piero L.L., Paolo B., et al. Sexual behavior and risk factors for the acquisition of human papillomavirus infections in young people in Italy: suggestions for future vaccination policies. BMC Public Health 2012; 12:623. http://www.biomedcentral.com/1471-2458/12/623

[50] Ismail S., Bitsuamlak H., Alemu K. High Risk Sexual Behaviors for STD/HIV, Pregnancies and Contraception among High School Students in a Rural Town, North Western Ethiopia. Ethiop J Health Dev 1997; 11(1):29-36.

[51] M. Nyirenda, V. Hosegood, M-L Newell. Age at first sex in rural South Africa. Sex Transm Infect 2009; 85(Suppl I):i49-i55.

[52] Derege K., Atalay A., Getnet M., Fikre E., Frehiwot B., Yigeremu A., et al. Khat and alcohol use and risky sex behaviour among in-school and out-of-school youth in Ethiopia BMC Public Health 2005, 5:109 doi:10.1186/14712458-5-109 
[53] Moges T.Substance abuse and sexual HIV-risk behaviour among Dilla University students, Ethiopia. Educational Research (ISSN: 2141-5161) November 2014; 5(9):368-374. http://www.interesjournals.org/ER 